\title{
PENGARUH PENGENCER DAN LAMA SIMPAN SEMEN AYAM KAMPUNG PADA SUHU RUANG TERHADAP MOTILITAS DAN VIABILITAS SPERMATOZOA
}

\author{
Egidius Ulus ${ }^{1}$, Enike Dwi Kusumawati ${ }^{2}$, Aju Tjatur Nugroho Krisnaningsih ${ }^{3}$. \\ Universitas Kanjuruhan Malang \\ Ulusegidius@gmail.com
}

\begin{abstract}
The study was conducted from February to April 2018 in the field laboratory and integrated laboratory of University Kanjuruhan Malang. The purpose of this research is to know the effect of diluent and timetorage of kampung chicken sperm at room temperature to motility and viability of spermatozoa. The diluent used was $\mathrm{NaCl}$, egg yolk tris aminomethane and no diluent with sperm duration of $0,3,6,9,12,15,18,21,24,27,30$ hours and 10 replications. This research method is experimental laboratory by using completely randomize design of factorial. The data obtained in the study will be analyzed using the method of analysis of variance. The results showed that there was no significant effect $(\mathrm{P}>0,05)$ of diluent, time storage as well as interaction between diluent and time storage to sperm motility and viability. Diluent and time storage which still maintain motility up to the minimum limit for $\mathrm{AI}$ was $\mathrm{NaCl}$ in 18 hours $(41,5 \%)$, egg yolk tris aminomethan and without diluent at 12 hours of time storage that was equal to $49 \%$ and $42 \%$. While the diluent and the time store that still can maintain viability up to the minimum limit for $\mathrm{AI}$ was $\mathrm{NaCl}$ and egg yolk tris aminomethan on the 18-hour (82.5\%), without diluent on the time storage 12 hours $(81.5 \%)$. It can be concluded that the optimum spermatozoa motility on $\mathrm{NaCl}$ diluent with 6 hours of time storage. While the optimum viability of the $\mathrm{NaCl}$ and egg yolk tris aminomethan on the time storage 18 hours.
\end{abstract}

Keywords : Spermatozoa, Kampung chicken, motility, viability.

\section{Pendahuluan}

Ayam Kampung mempunyai peran yang sangat besar bagi kehidupan masyarakat terutama di pedesaan dijadikan sebagai sumber daging, telur dan sebagai tambahan pendapatan. Pemeliharaan ayam Kampung mempunyai beberapa keuntungan dibandingkan dengan ayam Ras yaitu cenderung lebih kuat terhadap penyakit tertentu, mempunyai daya adaptasi yang tinggi terhadap lingkungan dan pemeliharaan yang relatif mudah. Produk ayam Kampung seperti telur dan daging mempunyai keistimewaan dan sukar digantikan oleh komoditi lain. Namun demikian ayam Kampung juga mempunyai beberapa kelemahan seperti pertumbuhan yang lambat, produksi rendah, masih mempunyai sifat mengeram, lambat dewasa kelamin, lamanya selang waktu bertelur akibat mengasuh anak dan rendahnya mutu genetik. Mengatasi kondisi yang menghambat produktivitas ayam Kampung, maka perlu dicari terobosan dengan berbagai bioteknologi sederhana, dan hasilnya dapat diketahui dalam waktu yang relatif singkat. Salah satu teknologi reproduksi untuk meningkatkan produktivitas ayam lokal dapat dilakukan dengan Inseminasi Buatan (IB).

Teknologi IB dapat digunakan untuk meningkatkan mutu genetik dan betina yang dapat dikawini oleh pejantan. Salah satu kelemahan spermatozoa ayam kampung yaitu volume spermatozoa yang diejakulasikan sedikit, namun mempunyai kelebihan 
konsentrasi yang tinggi (Bebas dan Laksmi, 2015). Oleh sebab itu, spermatozoa perlu diencerkan dengan tujuan untuk memperbanyak volume spermatozoa dan agar selama proses penyimpanan tidak terjadi penurunan kualitas secara drastis. Perlakuan seperti ini sangat penting agar program IB dapat dilaksanakan secara meluas.

Penggunaan tris aminomethan kuning telur, dan $\mathrm{NaCl}$ sebagai bahan pengencer spermatozoa ayam kampung pada suhu ruang merupakan salah satu usaha memperbanyak volume dan mempertahankan kualitas spermatozoa. Dilaporkan oleh Danang et al. (2012) bahwa ringer laktat dapat mempertahankan kualitas spermatozoa setelah proses koleksi. Pengencer membutuhkan antibiotik yang berguna mencegah perkembangan bakteri patogen yang dapat merusak spermatozoa ayam kampung. Salah satu upaya untuk mempertahankan daya fertilitas yang optimum bisa dilakukan dengan jalan penyimpanan semen pada suhu ruang dengan maksud penghambatan terhadap aktivitas metabolisme baik secara fisik maupun kimia dalam kecepatan yang rendah. Kualitas semen selama penyimpanan sebelum dilakukan IB sangat penting diketahui karena dapat memperkirakan sejauh mana daya hidup dan fertilitas spermatozoa di dalam saluran reproduksi betina. Selain itu dapat digunakan pula sebagai acuan untuk inseminator dalam hal penyediaan semen yang baik untuk diinseminasikan.

Keberhasilan inseminasi pada ayam sangat tergantung pada beberapa faktor, antara lain: strain ayam, umur, pengencer yang digunakan, derajat pengenceran atau dosis inseminasi, kualitas semen, deposisi semen, dan waktu inseminasi. Berbagai usaha dilakukan untuk memperoleh bahan pengencer yang cocok untuk semen ayam yang relatif murah, mudah didapat dan efektif untuk pengenceran dan penyimpanan sehingga dapat tahan lama hidup dengan kualitas yang tetap baik.

Balai Besar Inseminasi Buatan Singosari menggunakan pengencer tris aminomethan kuning telur sebagai bahan pengencer semen (Zenichiro, dkk., 2002). Menurut Isnaini dan Suyadi (2000) $\mathrm{NaCl}$ juga dapat digunakan sebagai bahan pengencer ayam Kedu serta mampu mempertahankan motilitasnya sampai 90 menit pada suhu kamar dengan nilai motilitas sebesar $55 \pm 8,4 \%$. Permasalahannya adalah berapa waktu optimal yang dibutuhkan untuk mengetahui lama simpan semen pada suhu ruang terhadap kualitas spermatozoa ayam Kampung dengan menggunakan pengencer tris aminomethan kuning telur, $\mathrm{NaCl}$ dan tanpa pengencer. 


\section{Materi dan Metode}

Metode yang digunakan dalam penelitian ini adalah penelitian laboratorium menggunakan Rancangan Acak Lengkap (RAL) faktorial. Perlakuan pada penelitian ini terdiri dari dua faktor yaitu:

1. Jenis Pengencer

Pengenceran yang digunakan dalam penelitian ini ada 2 jenis pengencer yaitu : $\mathrm{NaCl}$, Tris Aminomethan Kuning Telur.

2. Lama Simpan Semen

Lama simpan semen pada suhu ruang menggunakan sebelas waktu pengamatan yang berbeda yaitu pada jam ke $0,3,6,9,12,15,18,21,24,27$, dan 30. Masingmasing pengamatan diulang 10 kali.

\section{Hasil dan Pembahasan}

\section{Kualitas Semen Segar Ayam Kampung}

Pemeriksaan semen segar pada penelitian ini meliputi a) makroskopis antara lain volume, warna, kosentrasi, derajat keasaman, dan bau; b) mikroskopis antara lain motilitas massa, motilitas individu, viabilitas, kosentrasi, abnormalitas yang dapat dilihat pada Tabel 2.

Tabel 2. Kualitas semen segar

\begin{tabular}{ll}
\hline Kualitas Semen Segar & Rataan dan Standar Deviasi \\
\hline Makroskopis: & \\
Volume (ml) & $0,47 \pm 0,10$ \\
Warna & Putih \\
Konsistensi & Kental \\
pH & $7,35 \pm 0,52$ \\
Bau & Khas \\
Mikroskopis: & \\
Motilitas massa & \\
Motilitas individu (\%) & +++ \\
Viabilitas (\%) & $99 \pm 2,11 \%$ \\
Kosentrasi (x $10^{6} \quad$ sel & $99,1 \pm 0,88 \%$ \\
spermatozoa/ml) & $1.369,7 \pm 28,23$ \\
Abnormalitas (\%) & $1,3 \pm 0,48 \%$ \\
\hline
\end{tabular}

\section{Kualitas Semen Ayam Kampung Dengan Pengencer dan Lama Simpan Yang Berbeda}

Kualitas spermatozoa semen ayam kampung pada suhu ruang mengunakan pengencer dan lama simpan yang berbeda yang diamati pada penelitian ini meliputi motilitas, viabilitas dan abnormalitas.

\section{a. Motilitas}

\section{1) Motilitas Dengan Pengencer Yang Berbeda}


Hasil penelitian pada Tabel 3. semen segar ayam kampung pada suhu ruang dengan pengencer yang berbeda menunjukkan rataan presentase spermatozoa tertinggi yaitu $52,27 \pm 33,11 \%$ untuk pengencer $\mathrm{NaCl}$, sedangkan untuk pengencer tris aminomethan kuning telur dan tanpa pengencer, masing-masing memiliki presentae $42,18 \pm 33,98 \%$ dan $38,68 \pm 32,87 \%$.

Tabel 3. Rataan motilitas dengan pengencer yang berbeda

\begin{tabular}{lc}
\hline Pengencer & Motilitas (\%) \\
\hline Tanpa Pengencer & $38,68 \pm 32,87$ \\
$\mathrm{NaCl}$ & $52,27 \pm 33,11$ \\
Tris Aminomethan Kuning Telur & $42,18 \pm 33,98$ \\
\hline
\end{tabular}

Keterangan: Tidak adanya notasi menunjukkan tidak ada pengaruh pengencer terhadap viabilitas spermatozoa.

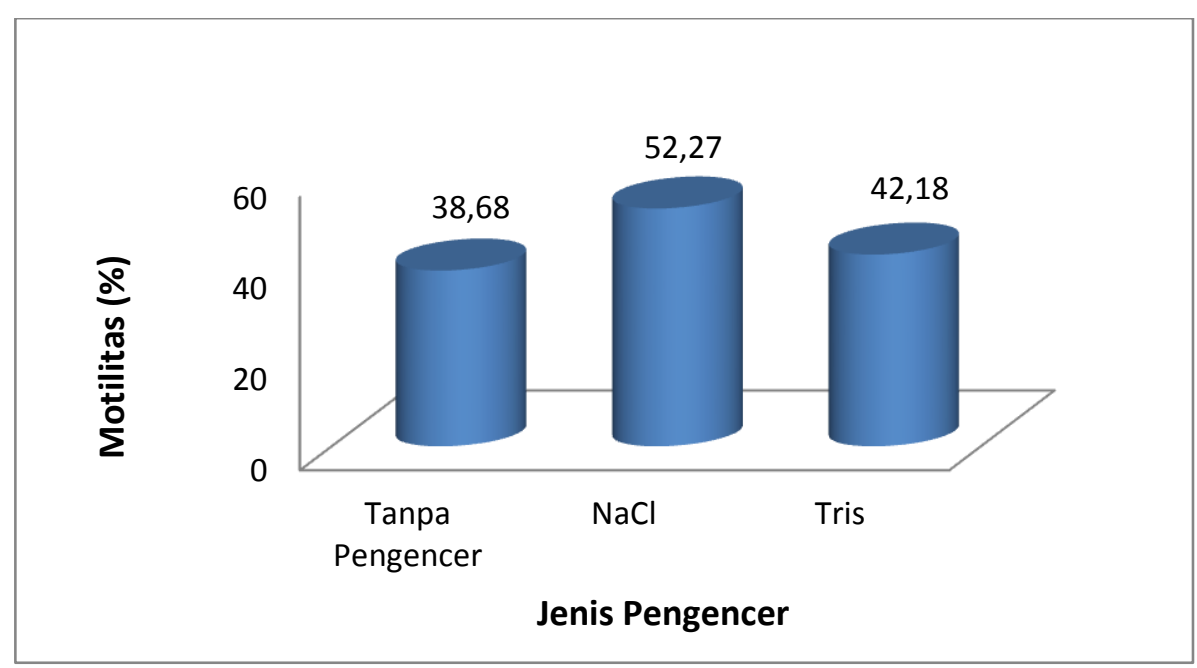

Gambar 1. Grafik motilitas spermatozoa pada suhu ruang dengan pengencer yang berbeda.

\section{2) Motilitas Dengan Lama Simpan Yang Berbeda}

Berdasarkan analisis data menunjukkan bahwa motilitas dengan lama simpan yang berbeda tidak terdapat pengaruh yang nyata $(\mathrm{P}>0,05)$ terhadap motilitas spermatozoa

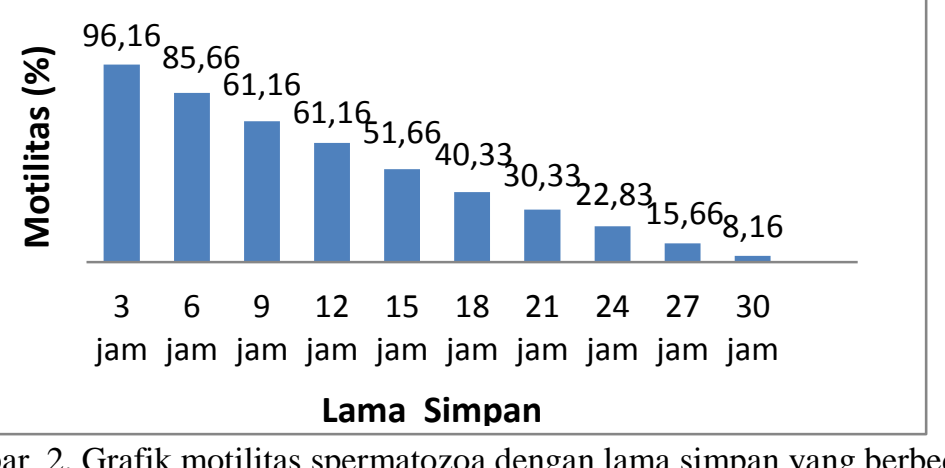

3) Motilitas pada Interaksi Pengencer dan Lama Simpan 
Motilitas dengan interaksi dan lama simpan yang terlihat pada Gambar 3. menunjukkan bahwa tidak terdapat pengaruh yang nyata $(\mathrm{P}>0,05)$ antara interaksi dan lama simpan semen.

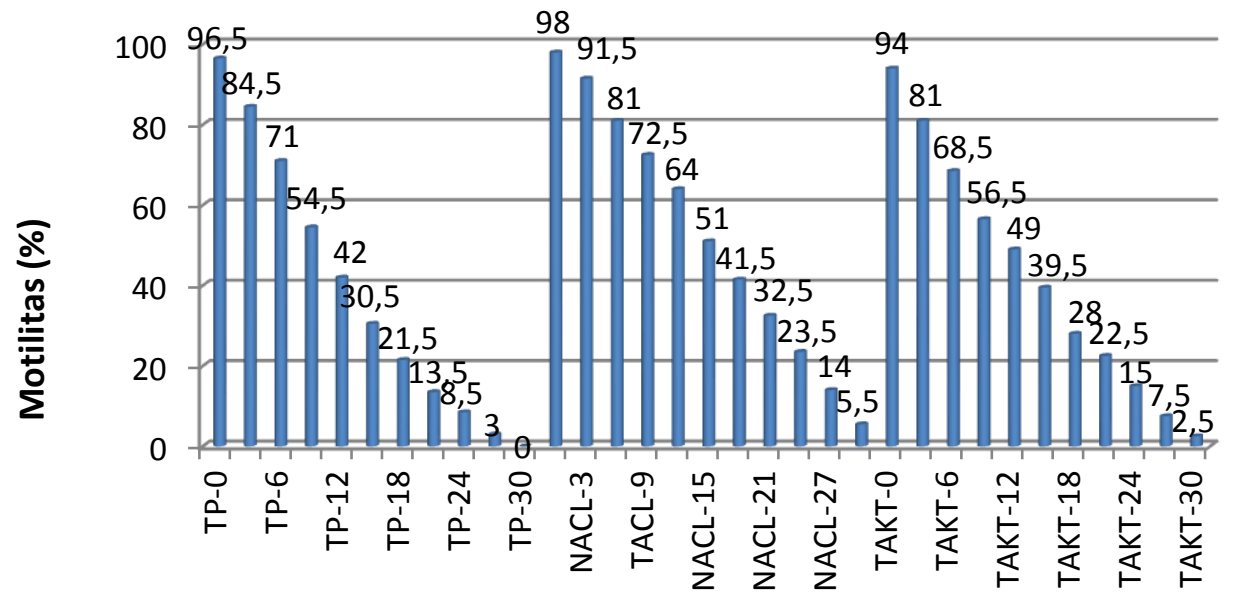

\section{Pengencer dan Lama Simpan}

Gambar 3. Grafik motilitas spermatozoa dengan interaksi dan lama simpan yang berbeda

\section{b. Viabilitas}

\section{Viabilitas Dengan Pengencer Yang Berbeda}

Peresentase viabilitas merupakan salah satu indikator untuk menentukan baik buruknya kualitas semen. Hasil analisis ragam menunjukkan bahwa pengaruh pengencer dan lama simpan semen tidak terdapat pengaruh yang nyata $(P>0,05)$ terhadap viabilitas spermatozoa ayam kampung.

Table 4. Rataan viabilitas dengan pengencer yang berbeda

\begin{tabular}{lr}
\hline Pengencer & Viabilitas (\%) \\
\hline Tanpa Pengencer & $77,81 \pm 14,05$ \\
$\mathrm{NaCl}$ & $84.1 \pm 14,17$ \\
Tris Aminomethan Kuning Telur & $84,1 \pm 14,45$ \\
\hline
\end{tabular}

Keterangan: Tidak adanya notasi menunjukkan tidak ada pengaruh pengencer terhadap viabilitas spermatozoa.

Pada Tabel 4. menunjukkan bahwa persentase viabilitas spermatozoa tertinggi adalah pengencer tris aminomethan kuning telur yaitu $84,1 \pm 14,45 \%$ diikuti dengan pengencer $\mathrm{NaCl} 84.1 \pm 14,17 \%$ dan yang tanpa pengencer persentase spermatozoanya yang terendah yaitu $77,81 \pm 14,05 \%$. 


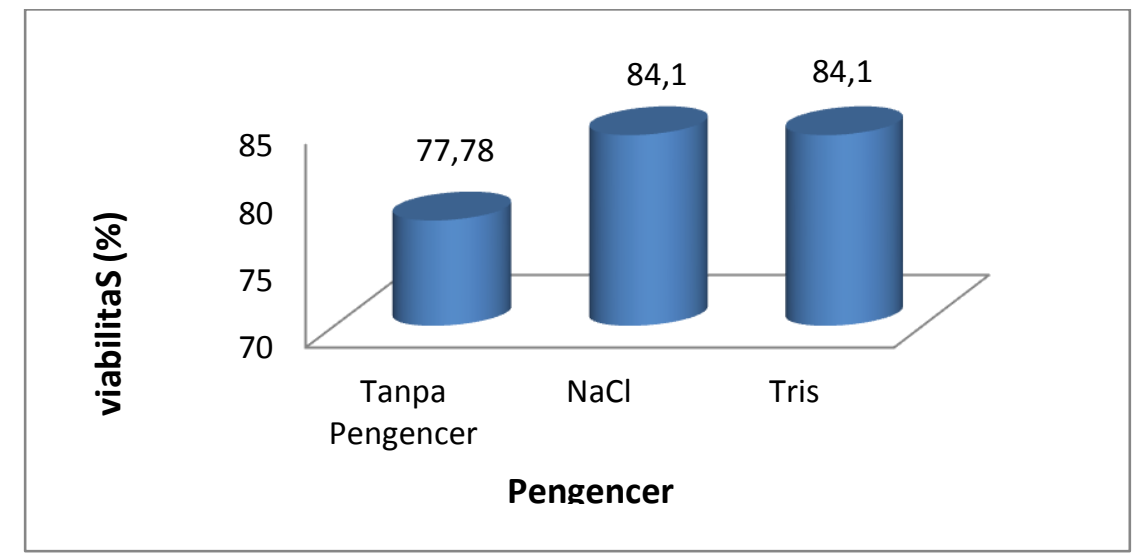

Gambar 4. Grafik viabilitas spermatozoa dengan pengencer yang berbeda

\section{Presentase Viabilitas Dengan Lama Simpan Yang berbeda}

Presentasi viabilitas dengan lama simpan yang berbeda menunjukkan bahwa tidak terdapat pengaruh yang nyata $(\mathrm{P}>0,05)$ terhadap viabilitas spermatozoa.

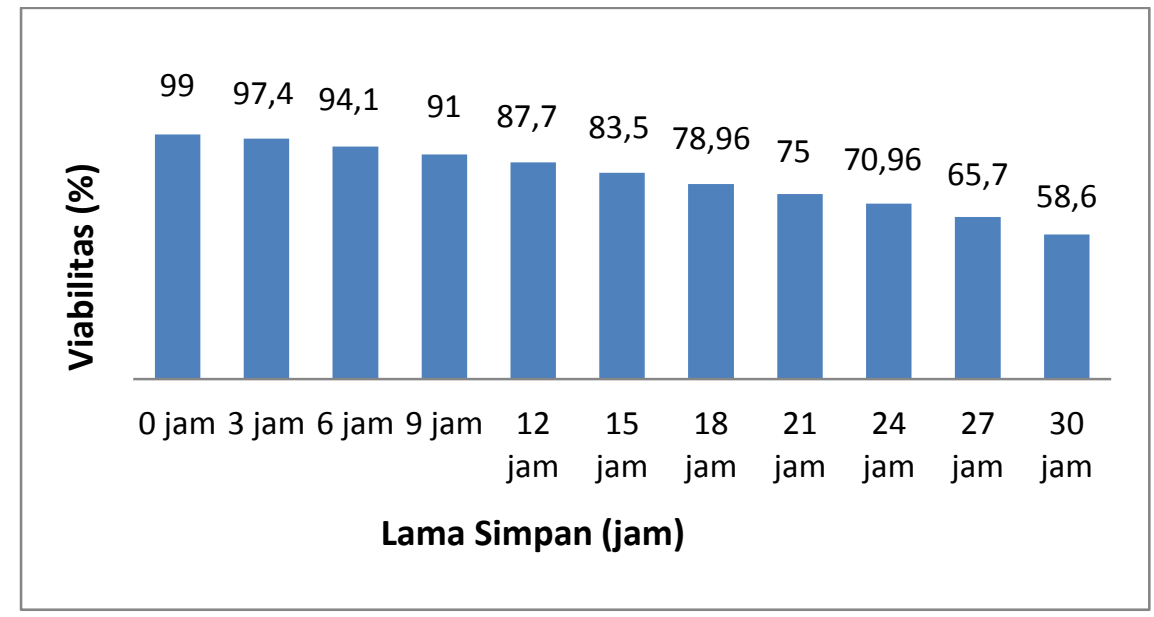

Gambar 5. Grafik viabilitas dengan lama simpan yang berbeda

\section{Viabilitas pada Interaksi antara Pengencer dan Lama Simpan}

Terlihat juga pada Gambar 6. menunjukkan bahwa tidak terdapat pengaruh yang tidak nyata $(\mathrm{P}>0,05)$ interaksi spermatozoa ayam kampung terhadap viabilitas spermatozoa pada suhu ruang. 


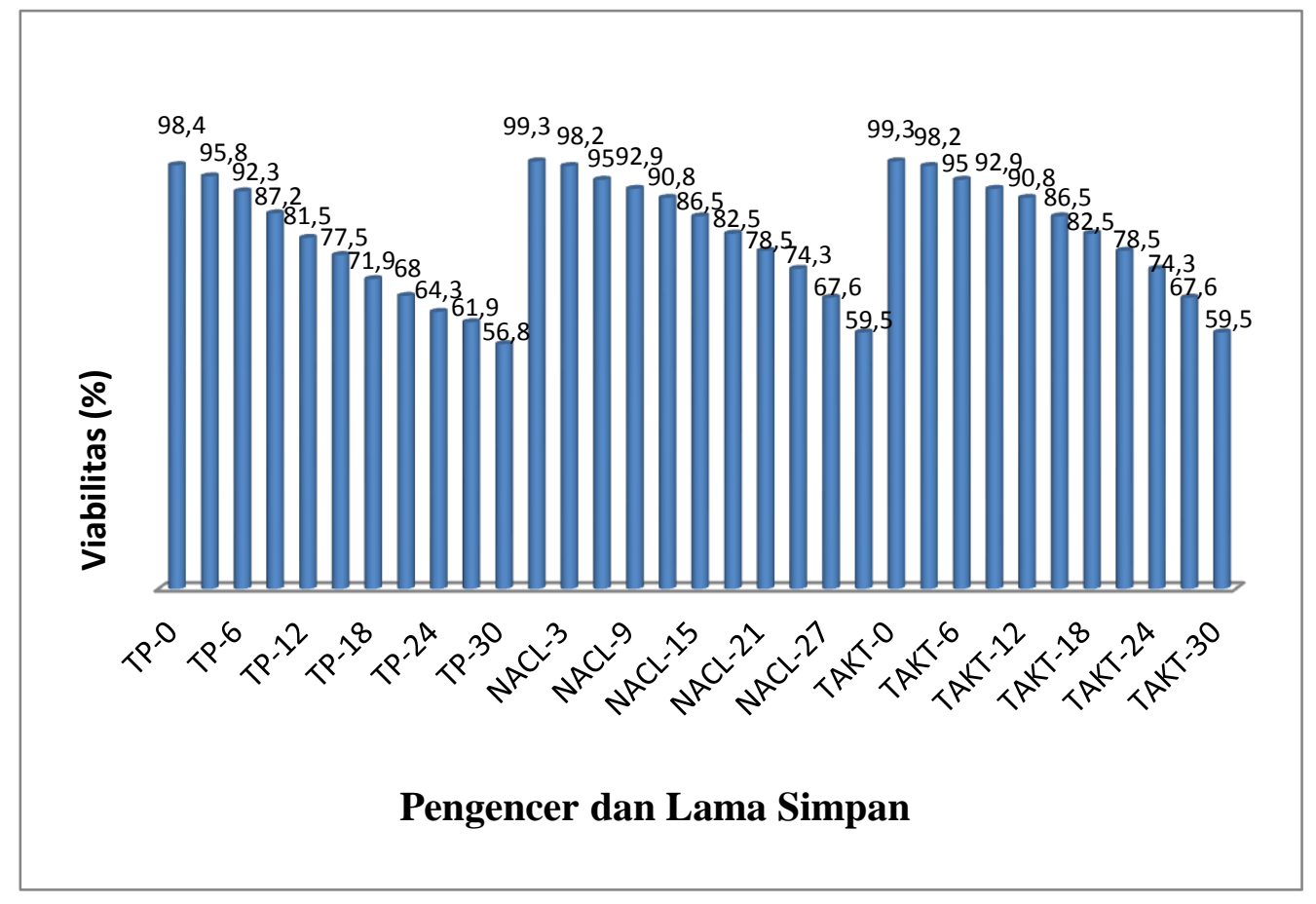

Gambar 6. Grafik viabilitas pada interaksi antara pengencer dan lama simpan

\section{A. Pembahasan}

\section{Kualitas Semen Segar Ayam Kampung}

Kualitas semen segar pada penelitian menunjukkan bahwa semen yang digunakan layak untuk peroses lebih lanjut. Presentase motilitas spermatozoa semen segar ayam kampung yang didapat dari pemeriksaan mikroskopis adalah 99\% dengan kosentrasi 1.369,7 juta spermatozoa/ml. Presentase motilitas dan kosentrasi semen yang digunakan sudah memenuhi persyaratan untuk proses lebih lanjut, karena presentase minimal motilitas dan kosentrasi yang dihasilkan harus $70 \%$ dan tidak kurang dari 500 juta spermatozoa/ml (Zenichiro, ddk, 2002).

\section{Kualitas Semen Ayam Kampung Dengan Pengencer dan Lama Simpan Yang Berbeda}

a. Motilitas

\section{1) Motilitas Dengan Pengencer Yang Berbeda}

Berdasarkan hasil evaluasi semen ayam kampung menunjukkan bahwa tidak terdapat pengaruh yang nyata $(\mathrm{P}>0,05)$ antara pengencer dengan motilitas spermatozoa pada suhu ruang. Motilitas spermatozoa ayam kampung pada suhu ruang dengan pengencer $\mathrm{NaCl}$, menunjukkan hasil yang baik, dibandingkan dengan pengecer TAKT dan tanpa pengencer. Menunjukan hasil 
yang baik ini karena lautan NaCL merupakan larutan yang Isotonis dengan plasma semen. Mengingat unsur kimia yang terkandung didalamnya hanya unsur elektrolit saja, yaitu Natrium dan Klorida. Untuk itu perlu ditambahkan bahan lain yang mengandung sumber energi bagi spermatozoa sehingga masa hidup spermatozoa dapat diperpanjang. Ini juga disebabkan pada sat pengenceran semen cuaca dan suhu ruang dalam keadaan stabil.

\section{2) Motilitas Dengan Lama Simpan Yang Berbeda}

Berdasarkan analisis data menunjukkan bahwa motilitas dengan lama simpan yang berbeda tidak terdapat pengaruh yang nyata $(\mathrm{P}>0,05)$ terhadap motilitas spermatozoa. Pada Gambar 2. juga menunjukkan terjadi penurunan yang signifikan dari jam ke 0-30. Gambar 2. juga menunjukkan bahwa terjadi penurunan yang drastis antara pengencer $\mathrm{NaCl}$ dan tris aminomethan kuning telur namun terjadi penurunan yang jauh terdapat di tanpa pengencer, dan penurunan kualitas semen ini dipengaruhi oleh cuaca dan suhu ruang yang tidak stabil, dan untuk yang tidak menggunakan pengencer terjadi penurunan disebabkan oleh suplai makanan pada semennya yang tidak ada dan dipengaruhi oleh cuaca maupun suhu ruang yang tidak stabil. Penyimpanan semen yang lebih lama akan semakin meningkatkan tingkat kematian spermatozoa karena rusaknya membran plasma yang berakibat pada terganggunya suplai energi spermatozoa sehingga menurunkan motilitas (Wiyanti dkk., 2013). Jumlah spermatozoa yang mati akan memengaruhi spermatozoa yang masih hidup selama proses penyimpanan (Solihati dkk, 2006).

\section{3) Motilitas pada Interaksi Pengencer dan Lama Simpan}

Motilitas dengan interaksi dan lama simpan yang terlihat pada Gambar 3. menunjukkan bahwa tidak terdapat pengaruh yang nyata $(\mathrm{P}>0,05)$ antara interaksi dan lama simpan semen. Pada Gambar 3. juga menunjukkan bahwa, motilitas semen dengan lama waktu simpan 18 jam $\mathrm{NaCl}$ dapat mempertahankan motilitas sampai batas minimum IB 41,5\%, sedangkan tanpa pengencer dan tris aminomethan kuning telur tidak dapat mempertahankan motilitas sampai batas minimum IB dengan nilai masing-masing $42 \%$ dan 49\%. Menurut Hafez (2008) syarat motilitas minimum untuk IB adalah $40 \%$.

\section{b. Viabilitas}

1) Viabilitas Dengan Pengencer Yang Berbeda. 
Pada Tabel 4. menunjukkan bahwa persentase viabilitas spermatozoa tertinggi adalah pengencer tris aminomethan kuning telur yaitu $84,1 \pm 14,45 \%$ diikuti dengan pengencer $\mathrm{NaCl} 84.1 \pm 14,17 \%$ dan yang tanpa pengencer

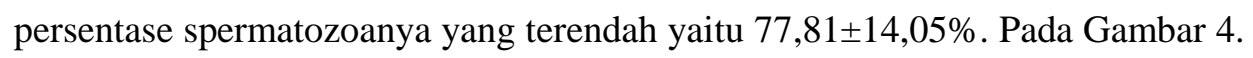
dibawah ini juga menunjukkan presentase viabilitas spermatozoa terjadi peningkatan pada pada pengencer tris aminomethan kuning telur, dengan $\mathrm{NaCl}$. Hal ini disebabkan pengencer $\mathrm{NaCl}$ dan Tris Aminomethan Kuning Telur mengandung komposisi pengencer yang lengkap diantaranya kuning telur yang berfungsi untuk suplai makanan.

\section{2) Presentase Viabilitas Dengan Lama Simpan Yang berbeda}

Presentasi viabilitas dengan lama simpan yang berbeda menunjukkan bahwa tidak terdapat pengaruh yang nyata $(\mathrm{P}>0,05)$ terhadap viabilitas spermatozoa. Pada Gambar 5. menunjukkan bahwa semakin lama penyimpanan spermatozoa maka akan semakin menurun. Menurunnya kualitas semen disebabkan oleh cuaca dan suhu ruang yang kurang stabil, dan untuk tanpa pengencer juga disebabkan oleh suplai makanan untuk semen tidak ada. Peresentase spermatozoa yang menurun seiring dengan bertambahnya lama simpan semen dipengaruhi oleh jumlah nutrisi spermatozoa dalam pengencer ikut mengalami penurunan, sehingga viabilitas spermatozoa ayam kampung mengalami penurunan. Danang dkk, (2012) menyatakan berkurangnya jumlah nutrisi spermatozoa disebabkan oleh penggunaan energi untuk aktivitas mekanik (gerak) dan kimiawai (biosintesa). Sesuai dengan pendapat Solihati dkk. (2006) bahwa semakin berkurangnya cadangan makanan, dan ketidakseimbangan cairan elektrolit akibat metabolisme spermatozoa dapat menyebabkan kerusakan membran sel spermatozoa.

\section{3) Viabilitas pada Interaksi antara Pengencer dan Lama Simpan}

Pada Gambar 6. menunjukkan bahwa tidak terdapat pengaruh yang tidak nyata $(\mathrm{P}>0,05)$ interaksi spermatozoa ayam kampung terhadap viabilitas spermatozoa pada suhu ruang. Pada Gambar 6. juga menunjukkan bahwa, viabilitas semen dengan lama waktu simpan 18 jam $\mathrm{NaCl}$ dan tris aminomethan kuning telur dapat mempertahankan viabilitas sampai batas minimum IB 82,5\%, sedangkan tanpa pengencer tidak dapat mempertahankan viabilitas sampai batas 
minimum IB dengan nilai $81,5 \%$. Syarat minimum viabilitas spermatozoa untuk IB adalah minimal 80\% (Pineda, 2003).

\section{Kesimpulan}

Berdasarkan hasil penelitian dapat disimpulkan bahwa motilitas spermatozoa yang optimum pada pengencer $\mathrm{NaCl}$ dengan lama simpan 18 jam. Sedangkan viabilitas yang optimum pada pengencer $\mathrm{NaCl}$ dan tris aminomethan kuning telur pada lama simpan 18 jam.

Perlu dilakukan kajian lebih lanjut tentang pengaruh pengencer terhadap kerusakan membran spermatozoa secara lebih dalam.

\section{Daftar Pustaka}

Bebas W, Laksi DNDI. 2015. Viabilitas spermatozoa ayam hutan hijau dalam pengencer posfat kuning telur ditanbah laktosa pada penyimpanan 50C. Jurnal Veteriner 16: 62-67.

Chandra, ddk., 2013. Perodusi Ternak Fakultas Peternakan Universitas Brawijaya Malang.

Danang, ddk., 2012. Reproduksi. Fakultas Peternakan Universitas Brawijaya Malang.

Danang D.R., Isnaini N, Trisunuwati P. 2012. Pengaruh lama simpan semen terhadap kualitas spermatozoa ayam kampung dalam pengencer ringer's pada suhu $4^{\circ} \mathrm{C} . J$ Ternak Tropika 13(1): 47-57.

Dadang MS, Sugiyatno. 2007. Pengaruh atas gliserol terhadap motilitas dan fertilitas spermatozoa ayam kampung yang dibekukan dengan nitrogen cair. Anim Product 1411-2027.

Ervandi M. 2011. Pengaruh bangsa ayam terhadap kualitas dan fertilitas spermatozoa (Tesis). Palu (ID): Universitas Tadulako.

Garner, D.L. and E.S.E. Hafez. 2000. Spermatozoa and Seminal Plasma. In: Reproduction in Farm Animal. 7th ed. Lea and Febringer, Philadelphia.

Hardjopranjoto, s. 1976. Ilmu Insiminasi Buatan. Edisi kedua. Fakultas Kedokteran Hewan Unair Surabaya.

Hardijanto, 1991. Inseminasi Buatan pada Unggas. Fakultas Kedokteran Hewan. Universitas Airlangga Surabaya.

Hafez, E.S.E. 2008. Preservation and Cryopreservation of Gametes and Embryos. In: Reproduction in Farm Animals. Hafez, E.S.E. 7th ed. Lippincott Williams and Wilkins. Awollers Kluwer Company. Philadelphia: 431-442.

Hafez, E.S.E. 2008. Preservation and Cryopreservation of Gametes and Embryos. In: Reproduction in Farm Animals. Hafez, E.S.E. 7th ed. Lippincott Williams and 
Wilkins. Awollers Kluwer Company. Philadelphia: 431-442. Hafez, E.S.E. 2008. Preservation and Cryopreservation of Gametes and Embryos. In: Reproduction in Farm Animals. Hafez, E.S.E. 7th ed. Lippincott Williams and Wilkins. Awollers Kluwer Company. Philadelphia: 431-442.

Ihsan, N.M. 2009. Bioteknologi Reproduksi Ternak. Universitas Brawijaya. Malang.

Isnaini, N., \& Suyadi. 2000. Kualitas Semen Ayam Arab Dalam Berbagai Lama Penyimpanan Suhu Kamar. Jurnal Tropika volume 1 nomor 1. Fakultas Peternakan. Universitas Brawijaya Malang.

Isnaini, N. 2000. Kualitas semen ayam Arab dalam pengencer $\mathrm{NaCl}$ fisiologis dan Ringer's pada suhu kamar. J. Habitat. 11(13) : 233 -237.

Kusumawati, dkk., 20016. Seminar Nasional Hasil Penelitian, 2016. Pengaruh suhu dan lama simpan semen segar terhadap motilitas dan abnormalitas spermatozoa kambing peranakan etawa (pe)

Kartasudjana, R. 2001. Seminar Nasional Hasil Penelitian. Ciri-ciri atau Tanda Keabnormalitasan pada Semen Kambing Peranakan Etawa (PE).

Kartasudjana. R 2001. Teknik Insiminasi Buatan Pada Ternak. Modul Program Keahlian Pada Ternak Depertemen Pendidikan Nasional Pada Proyek Pengolaan Sistem Stndar. Diretorat Pendidikan Jakarta.

Latif, A., Ijaz, A., Aleem, M., dan Mahmud, A. 2005. Effect of osmotic pressure and pH on the short-term storage and fertility of broiler breeder sperm. Pakistan Vet. J. 25(4): 179-182.

Marawali, A, M.H Thomas, Burhanuddin dan H.L.L Belli. 2001. Dasar-dasar Ilmu Reproduksi Ternak. Departemen pendidikan nasional. Direktorat Jenderal Pendidikan Tinggi. Badan Kerjasama Perguruan Tinggi Negeri. Indonesia Timur. Kupang.

Mayasta, ddk., 2014. Laboratorium Reproduksi Veteriner Fakultas Kedokteran Hewan, Universitas Udayana.

Nurcholidah S., R. Idi, R. Setiawan, I.Y. Asmara, B.I. Sujana., 2006. Lama Penyimpanan Semen Cair Ayam Buras pada Suhu 5 oC terhadap Periode Fertil dan Fertilitas Sperma. http://pustaka.unpad.ac.id.

Nurfirman. 2001. Efektifitas Medium Beltsville Poultry Semen Extender (BPSE) terhadap Kualitas Semen Cair Ayam Lokal. http://repository.ipb.ac.id.

Saleh DM. 2004. Optimization of semen processing and cryopreservation technique in Philipphine Native Roosters (Gallus gallus domesticus L). (Disertasion). Los Banos: University of the Philipphine Los Banos.

Suidzinska, A, Lukaszewicz E. 2008. The effect of breed on freezability of semen of fancy fowl. Anim Sci Pap Rep 26: 331-340.

Solihati, N,R. Idi, R. Setiawan, I.Y. Asmara. 2006. Pengaruh Lama Penyimpanan Semen Cair Ayam Buras Pada Suhu 50C terhadap Priode Fertil dan Fertilisasi Sperma. 
Situmorang,ddk., 2014. Fakultas Kedokteran Hewan, Universitas Udayana.

Susilawati, T. 2011. Spermatology.Universitas Brawijaya Press. Malang. ISBN: 978-6028960-04-5.

Suyadi, A. Rachmawati, N. Iswanto. 2012. Pengaruh $\alpha$-Tocopherol yang Berbeda dalam Pengencer Dasar Tris Aminomethanekuning Telur Terhadap Kualitas Semen Kambing Boer yang Disimpan pada Suhu 50C. Jurnal Ilmiah Ilmu-ilmu Peternakan. 22 (3): 1-8.

Sutiyono. S, Riyadi dan S, Kismiati. 2006. Fertilisasi dan Daya Tetas Telur dari Ayam Petelur Hasil Inseminasi buatan Menggunakan Semen Ayam Kampung yang Diencerkan dengan Bahan Berbeda. http://eprints.undip.ac.id.

Suprijatna, E., Atmomarsono, U., dan Kartasudjana, R., 2005. Ilmu Dasar Ternak Unggas. Penebar Swadaya, Jakarta.

Solihati, N., R. Idi, R. Setiawan, dan I.Y. Asmara. 2006. Pengaruh Lama Penyimpanan Semen Cair Ayam Buras pada Suhu 5o C terhadap Periode Fertil dan Fertilisasi Sperma. http://pustaka.unpad.ac.id.

Widya A, Kustono, Widayati TA, Bintara S, Ismaya. 2013. Pengaruh dosis sperma yang diencerkan dengan NACL fisiologis terhadap fertilitas telur pada inseminasi buatan ayam Kampung. Bul Peternakan 37(1): 1-5.

Wiyanti D.C. Isyani N. dan Trisunuwati P. 2013. Seminar Nasional Hasil Penelitian. Pengaruh Lama Simpan Semen Dalam Pengencer $\mathrm{NaCl}$ Fisiologis Pada Suhu KamarTerhadap Kualitas Spermatozoa Ayam Kampung (Galus domestic).

Yunarawati, S. 2001. Pengaruh Lama Simpan Terhadap Kualitas Simpan Ayam Kedu dalam Pengencer Ringer's pada Suhu 4 OC. Skripsi. Fakultas Peternakan. Universitas Brawijaya. Malang.

Zenichiro, K. 2002. Teknologi Prosesing Semen Beku Pada Sapi. Malang : JICA- Balai Inseminasi Buatan Singosari. Seminar Nasional Hasil Penelitian.

Zenichiro, K., Herliantien dan Sarastina. (2002). Teknologi Prosesing Semen Beku Pada Sapi. Balai Besar Inseminasi Buatan Singosari. Malang.

Zenichiro, dkk, 2002. Konsistensi atau Kekentalan pada Semen Kambing Peranakan Etawa (PE). 